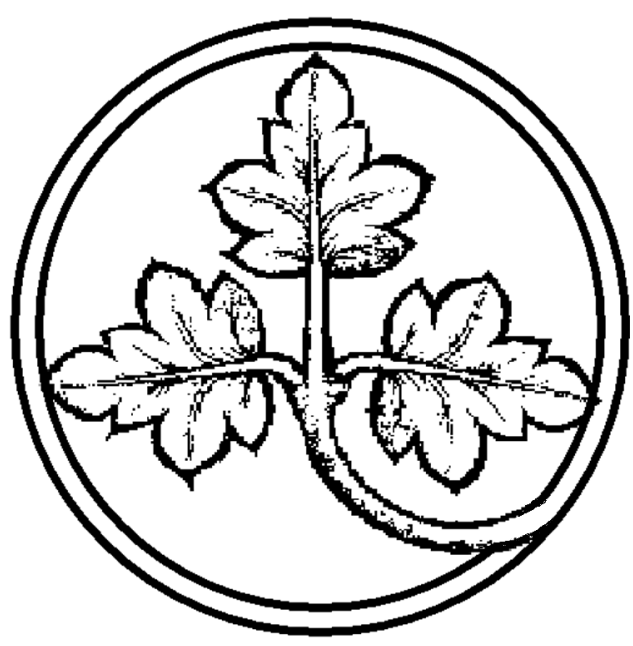

\author{
Preprints of the \\ Max Planck Institute \\ for Research on Collective Goods \\ Bonn \\ 2005/3
}

Switching Costs in Retroactive Rebates What's time got to do with it?

Frank P. Maier-Rigaud 


\section{Switching Costs in Retroactive Rebates - What's time got to do with it?}

Frank P. Maier-Rigaud

February 2005 


\title{
Switching Costs in Retroactive Rebates - What's time got to do with it?*
}

\author{
Frank P. Maier-Rigaud ${ }^{\dagger}$
}

February 9, 2005

\begin{abstract}
This paper analyzes the role of the reference period in assessing switching costs in retroactive rebates. A retroactive rebate allows a firm to use the inelastic portion of demand as leverage to decrease price in the elastic portion of demand, thereby artificially increasing switching costs of buyers. I identify two factors that determine the extent to which retroactive rebates, as a form of infra-personal price-discrimination, can result in potential market foreclosure. These two factors are the rebate percentage and the threshold at which this percentage is retroactively applied. In contrast to the existing literature, the length of the reference period within which a rebate scheme applies is demonstrated to be at best an indirect approximation of the potential foreclosure effects of a rebate.
\end{abstract}

JEL-Classifications: L42, K21, D43.

Keywords: Retroactive rebates, article 82 ECT, reference period, infrapersonal price discrimination, foreclosure.

*Forthcoming in the European Competition Law Review.

${ }^{\dagger}$ Department of Economics, Indiana University Bloomington, USA; Max Planck Institute for Research on Collective Goods, Bonn, Germany; European Commission, Directorate General Competition, Brussels, Belgium; e-mail: maier-rigaud@microeconomics.de. I would like to thank Martin Beckenkamp, Benoit Durand, Christoph Engel, Eric Gippini Fournier, Guido Kordel, Lars Kjølbye, Kirti Mehta, Luc Peeperkorn, Chiara Ronzi, Christian Roques, Burkhard Schipper, Ingolf Schwarz, Andreas Seip and Carl Christian von Weizsäcker for comments on an earlier version of this paper. The views expressed are those of the author and not of the European Commission. 


\section{Introduction}

This paper does not aim at taking a position in the ongoing policy debate on retroactive rebate systems as exclusionary abuse under article 82 of the Treaty establishing the European Community (ECT), but solely focuses on the mechanics of retroactive rebates and the potential of such rebates to create switching costs that in turn may foreclose competition. The paper therefore only addresses the economic question of what aspects of retroactive rebates contribute to an increase in switching costs and what variables a competition authority interested in analyzing foreclosure effects or developing policy should look at.

In principle any economic analysis of retroactive rebates involves as a first step the identification of the switching costs created by the scheme. Whether the existence of switching costs actually results in (or legally implies) market foreclosure and whether this market foreclosure leads to (or legally implies) significant anti-competitive effects is a different question that will not be addressed in this paper.

Irrespective of the lack of consensus whether a particular retroactive rebate system can be qualified as an exclusionary abuse under article 82 ECT or not, there appears to be some agreement that the length of the reference period is an essential factor for assessing retroactive rebate systems. In particular it is often claimed that the longer the reference period and the more time of that reference period has already elapsed, the higher the switching costs and as a result also the potential foreclosure effect will be.

The present paper argues that the length of the reference period in rebate schemes is irrelevant for the economic assessment of switching costs and a potential foreclosure effect. As will be demonstrated in an informal way, the only relevant variables for assessing switching costs in retroactive rebate schemes are the threshold level at which the retroactive rebate applies and the rebate percentage. Switching costs are then an increasing function of the rebate percentage 
and the amount of units already bought from the dominant firm.

The remainder of the paper is organized as follows. I first discuss the existing view on the role of the time frame in retroactive rebates. I then turn to the mechanics of retroactive rebates and discuss what factors actually matter in assessing switching costs. I conclude with a brief summary of results.

\section{The Perceived Role of the Reference Period}

The growing literature on rebates is mostly concerned with a general assessment of rebate schemes with a more or less pronounced emphasis on economic effects analysis. This literature is often directly targeted at competition policy development. Maybe it is due to the breadth of the approaches that careful attention to the details of an economic analysis is often not provided. Before discussing this literature, it is useful to consider the role the reference period in retroactive rebate schemes has played in the pertinent Court cases.

The key court cases with respect to rebates schemes and in particular the length of the reference period in rebates are Michelin I and II. ${ }^{1}$ In Michelin I the Court argued that "..any system under which discounts are granted according to the quantities sold during a relatively long reference period has the inherent effect, at the end of that period, of increasing pressure on the buyer to reach the purchase figure needed to obtain the discount or to avoid suffering the expected loss for the entire period." 2 . In Michelin II the Court consequently stated that "..it cannot be denied that the loyalty-inducing nature of a system of discounts calculated on total turnover achieved increases in proportion to the length of the reference period." 3

Besides these Court cases, a lack of clarity in assessing rebates is also common

\footnotetext{
${ }^{1}$ Michelin I [1983] E.C.R. 3461, Michelin II [2003] E.C.R. 0.

${ }^{2}$ Michelin I [1983] E.C.R. 3461 para. [81].

${ }^{3}$ Michelin II [2003] E.C.R. 0. para. [88].
} 
in the literature on competition policy. A significant portion of this literature has failed, despite its critical attitude towards Court and Commission decisions, to fully understand the mechanics of retroactive rebates. The root of this mistake is probably found in the role of the reference period in assessing exclusive dealing. A somewhat undifferentiated treatment of exclusive dealing issues mixed together with rebates that is characteristic for the confusion, can be found in Hoffmann-La Roche. $^{4}$

Consider, for example, the article by Kallaugher and Sher ${ }^{5}$ that strongly argues in favor of an economic approach regarding rebates. In that paper the authors write:

"The first step would be to consider whether the system does generate substantial switching costs. We would suggest that a system with reference periods of three months or less is unlikely to create such costs, as long as the customer has a credible ability to switch to a rival supplier at the end of the period." 6

It is hard to see how the assessment of a rebate schemes' switching costs has anything to do with what happens after that scheme is no longer in place. In addition, the ability to switch in-between identical schemes should not be different from the ability to switch to a rival supplier right from the start of the scheme.

In the draft version of this paper presented at the Competition Law Forum in London in 2003 the following passage can be found:

"A third factor involves the duration and durability of the customer commitments that create switching cost. A rebate scheme with an annual reference period may impose high switching costs on the customer

\footnotetext{
${ }^{4}$ Hoffmann-La Roche [1979] E.C.R. 461.

${ }^{5}$ John Kallaugher and Brian Sher (2004) Rebates Revisited: Anti-Competitive Effects and Exclusionary Abuse Under Article 82, ECLR, 5. 263-285.

${ }^{6}$ Ibid. p. 280.
} 
at the end of that period, but those costs drop to zero at the beginning of the new period."7

The appendix of this version of the paper (footnote 30 in the published version) is also full with statements that claim that incentives to continue to buy from the dominant firm "grow stronger during the course of the rebate period and is particularly acute towards the end of the period" 8 and that "there is a clear suction effect towards the end of a rebate period, as recognized in Michelin I". ${ }^{9}$

In an otherwise useful discussion of the economics of rebates O'Donoghue ${ }^{10}$, first correctly argues that "One issue that has received undue attention is the length of the reference period over which the target is assessed" only to revert to the idea that "..beyond the rather obvious point that the longer the reference period is, the greater the customer's marginal incentives to buy from the dominant firm will be towards the end of the period." a few sentences later. The confusion is then completed with the statement that "..if the proportion of buyers' requirements affected by the dominant firm's loyalty schemes is relatively small, the length of the reference period is generally irrelevant. Conversely, if a large number of available buyers and their requirements are affected by loyalty schemes, the reference period may be one of several other elements that it will be appropriate

${ }^{7}$ John Kallaugher and Brian Sher (2003:26) Discounts as Exclusionary Abuse under Article 82: Reflections on Gyselen, working paper. Part of this paper is a discussion of Gyselen (Luc Gyselen (2004) Rebates: Competition on the Merits or Exclusionary Practice?, European Competition Law Annual: What is an Abuse of a Dominant Position?, forthcoming) who also emphasizes the relevance of the reference period as an important parameter in assessing foreclosure.

${ }^{8}$ Ibid. page 39 .

${ }^{9}$ Ibid. page 42 .

${ }^{10}$ Robert O'Donoghue (2003) Over-Regulating Lower Prices: Time for a Rethink on Pricing Abuses under Article 82 EC, working paper. See also John Temple Lang and Robert O'Donoghue (2002) Defining legitimate competition: how to clarify pricing abuses under Article 82, Fordham International Law Journal. In that article, the authors write "Generally, the longer [the length of the reference period] is, the greater the cumulative effect of the discount will be in absolute terms." After citing some pertinent cases they conclude that "there is no general rule beyond the fact that a longer period will tend to greater exclusion." See also Christian Roque (2004) CFI Judgment, Case T-203/01, Manufacture Française des Pneumatiques Michelin v Commission, ECLR, 11. 688-693. 
to have regard to." In addition to revealing a fundamental misunderstanding concerning the mechanism underlying retroactive rebate systems, this quote also reveals a confusion between the assessment of the effects of a particular rebate scheme and the overall situation in the market, that is, the percentage of market covered $^{11}$ by rebate schemes and for how long such schemes were used.

\section{Retroactive Rebates: Lack of Monotonicity and Continuity}

Consider the following simple rebate scheme ${ }^{12}$ where a certain rebate $\alpha \in(0,1]$ is granted retroactively on all units bought if the threshold $x^{T} \in \mathbb{Z}_{++}$is reached within the time frame $T$. Assuming a unit price $p \in \mathbb{R}_{++}$, all units up to the threshold cost $p$. As soon as $x^{T}$ is reached, any consecutive unit will have a price of $p^{T}:=(1-\alpha) p$. More specifically, the first $x^{T}-1$ units have a price of $p$, but the extra unit to reach $x^{T}$ has a price of $p-x^{T} \alpha p$. From unit $x^{T}+1$ on the price is $p^{T}:=(1-\alpha) p$ which coincides with the ex post average price if the threshold is reached.

As can be seen in Figure 1, retroactive rebates by definition result in noncontinuous and non-monotonic pricing schedules, that is, marginal price abruptly

\footnotetext{
${ }^{11}$ Note that substantial attention is usually given to the coverage of rebate schemes as a percentage of the overall market in assessing foreclosure. From an economic point of view, there is no reason to believe that this is one of the key factors or even the only factor determining market foreclosure.

${ }^{12}$ In general, rebates can be simple in the sense that they only specify a single threshold (common in individualized schemes), or they can be complex in that they define a host of threshold steps with different rebate percentages kicking in retroactively at respective levels. Threshold levels can be spelled out as minimum number of units of one or several goods or as a minimum sales value that needs to be reached for the rebate to be applicable. Rebates can in turn be given as price reductions or in kind rebates. Without lack of generality only single threshold schemes will be considered in the following. The analysis of complex rebates is more involved but not systematically different from the analysis presented here. In order to keep the analysis as simple as possible, multi-product rebates that raise tying issues will not be addressed. Furthermore the significance of switching costs may also depend on whether goods are bought for resale or not. Demand effects are not addressed because they do not provide additional insights into the mechanics of rebate schemes.
} 
Figure 1: Typical non-monotonic price schedule

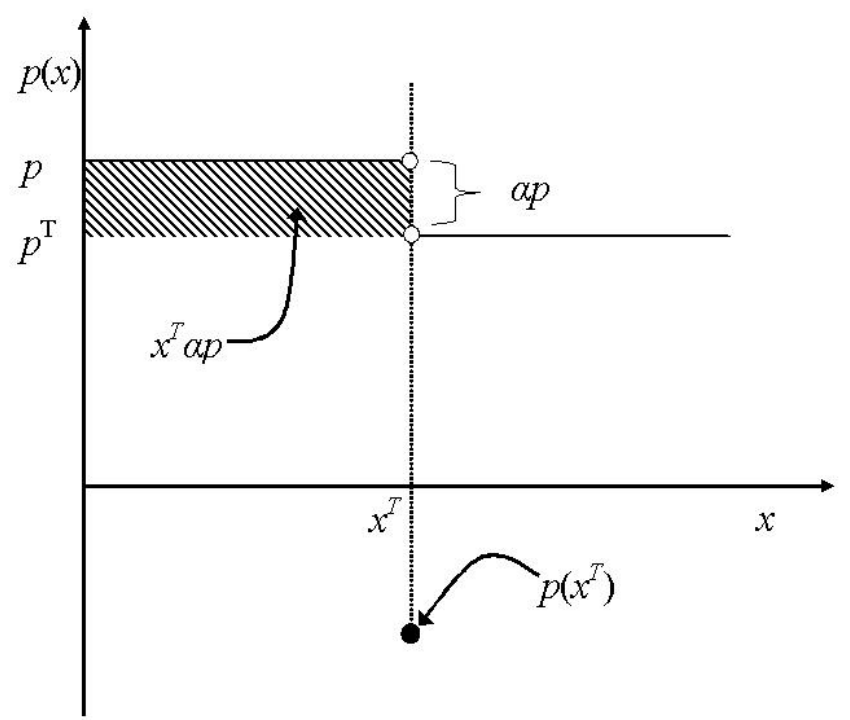

falls at $x^{T}$ (potentially below marginal cost or even below zero) and rises again afterwards. ${ }^{13}$

With knowledge of $p, x^{T}$ and $\alpha$, and holding demand constant, the impact of the retroactive rebate on the incentive structure of the buyer can easily be analyzed. Indeed, the impact of the retroactive rebate depends on $\alpha$ and $x^{14}$ :

$$
p\left(x^{*}\right):=\frac{p\left(x^{*}-\alpha x^{T}\right)}{x^{*}} .
$$

where $p\left(x^{*}\right)$ is the effective unit price (as opposed to transaction price) that the dominant firm charges for a remaining quantity of $x^{*}$ up to $x^{T}$. As is easily

\footnotetext{
${ }^{13}$ The non-linearity of the pricing scheme is probably the reason rebate schemes are often treated as being similar to two-part tariffs. Such resemblance is, however, superficial. The crucial feature of rebate scheme pricing schedules is the lack of monotonicity that is not found in other non-linear pricing schemes.

${ }^{14}$ Where $x$ denotes the amount already bought from the dominant firm and $x^{*}$ the remaining quantity up to the threshold so that $x:=x^{T}-x^{*} \forall x^{*} \leq x^{T}$ with $x, x^{*} \in \mathbb{Z}_{+}$.
} 
checked by setting $x^{*}=x^{T}$, this expression reduces to $p^{T}$. The expression can also be interpreted as the incentives the buyer faces not to switch (switching costs) to products from a competitor and consequently the prices a competitor would need to offer for the remaining $x^{*}$ units in order to match the dominant firm's pricing scheme.

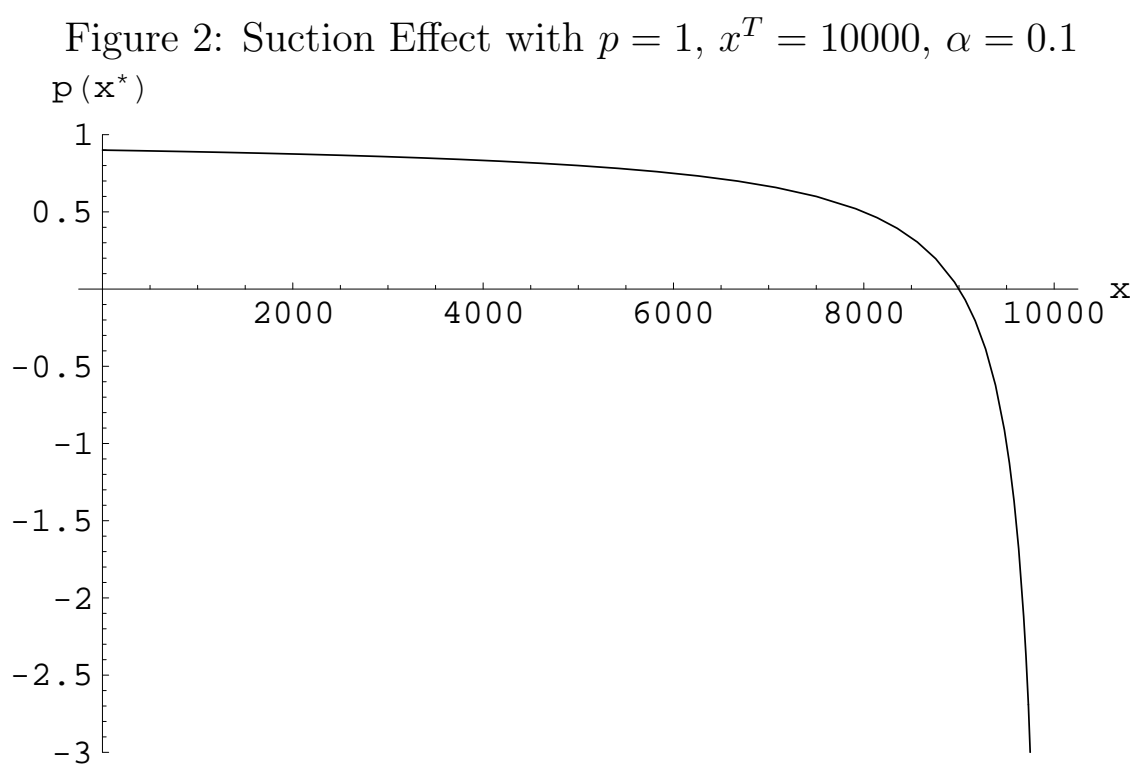

A two-dimensional graphical analysis for real valued quantities is provided in Figure 2 for $p=1, x^{T}=10000$ and $\alpha=0.1$. The Figure depicts the unit price as a function of $x$, that is, the more units have already been bought from the dominant firm, the lower the unit price for all the remaining units will be.

Figure 3 provides the corresponding three-dimensional graph for a range of rebate rates $(\alpha \in[0,0.5])$ inlcuding a plane at $p\left(x^{*}\right)=0$. Both Figures clearly indicate that marginal prices may become negative towards the threshold.

Consider now the introduction of a reference period of length $T$. At time $t=1, \gamma_{1} x^{T}$ units and at time $t=2, \gamma_{2} x^{T}$ units have been bought. Where $t \in\{1,2, . ., \hat{t}, . ., T\}$ and $\gamma_{t}:=\frac{x_{t}}{x^{T}}$ that is, $\gamma_{t} \in[0,1] .{ }^{15}$ To consider the potential

\footnotetext{
${ }^{15}$ Clearly, $x_{t}$ denotes the units already bought at time $t$.
} 
Figure 3: Suction Effect with $p=1, x^{T}=10000, \alpha \in[0,0.5]$

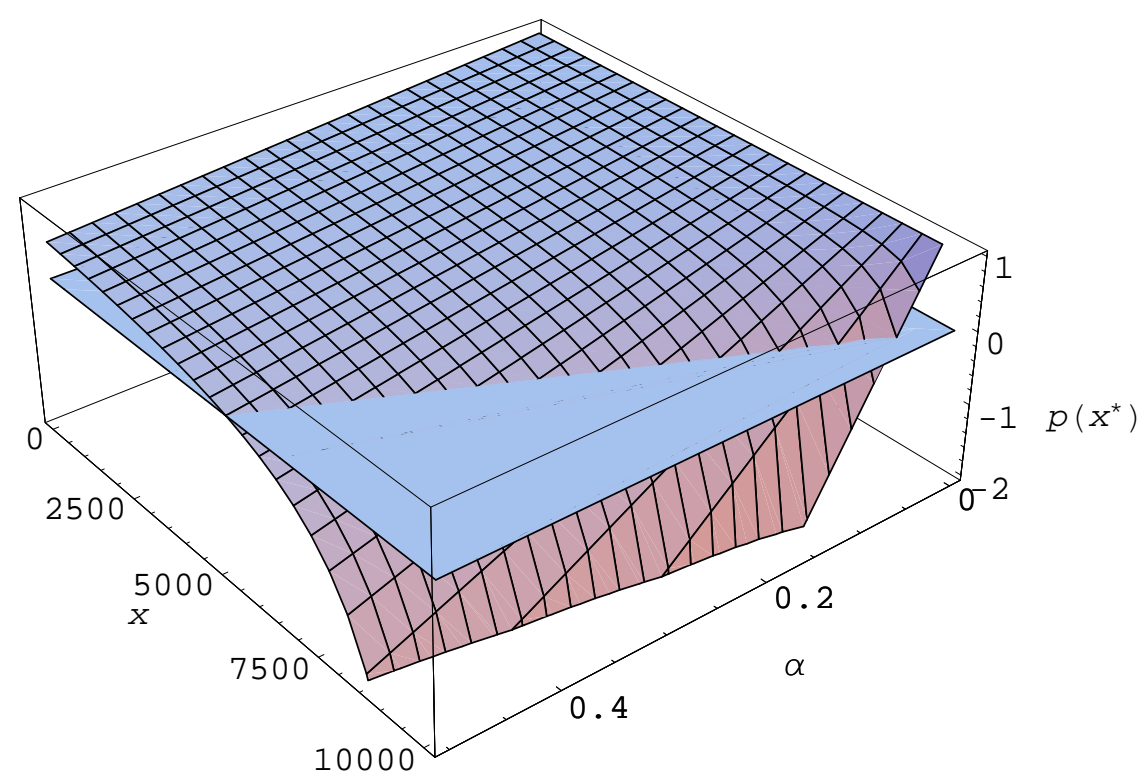

role of a reference period, two aspects need to be distinguished. First, the length of the reference period, that is, $T$ may matter. Second, it may matter how much time within the reference period remains, or in other words at what stage $t$ the switching costs are calculated.

Consider the switching costs at $t=\hat{t}$. If $\gamma_{\hat{t}}<1$, the rebate threshold has not been reached and switching costs can be calculated. Is it possible to draw any conclusions as to the switching costs from a knowledge of $\hat{t}$ ? We know that $\gamma_{\hat{t}-1} \leq \gamma_{\hat{t}}$, i. e., that quantity is non-decreasing in time, so that switching costs are non-decreasing in time as well. Without knowledge of $\gamma_{\hat{t}}$, switching costs at $\hat{t}$ cannot be calculated. The same holds for $T$. Again $\gamma_{\hat{t}}$ needs to be known and knowledge of $T$ alone does not allow the calculation of switching costs. In fact $T$ could be any positive real number ceteris paribus. ${ }^{16}$

\footnotetext{
${ }^{16}$ Imagine, for example, a rebate scheme for Christmas trees. Imagine further that Christmas trees are only bought in December. Given the product, the reference period of the scheme $(T)$ could well be specified either as the full year, or alternatively as December, without having any impact on switching costs.
} 
Excluding boundedly rational behavior ${ }^{17}$ on the buyers side, as, for example, time preference inconsistencies, the index $t$ can be dropped because it does not contribute to the analysis of switching costs. ${ }^{18}$ Note that this also holds under uncertainty $^{19}$, that is, under conditions of stochastic demand. At any $t$, switching costs are determined by the probability $\mu \in(0,1)$ of reaching $x^{T 20}$ and the factors discussed above. The effective unit price (as opposed to transaction price) that a dominant firm charges for a remaining quantity of $x^{*}$ up to $x^{T}$ under uncertainty is given by:

$$
\mu p\left(x^{*}\right)+(1-\mu) p
$$

As before, this expression can be interpreted as the price a competitor would need to offer for the remaining $x^{*}$ units. If $\mu=1$ this expression reduces to (1). Note that by definition $p\left(x^{*}\right)<p$, so that switching costs are lower under uncertainty. $^{21}$ Since the seller offering the rebate scheme in a situation of uncertainty may be able to adjust to this, it does not follow that the identification of demand uncertainty is sufficient to conclude that switching costs will tend to

\footnotetext{
${ }^{17}$ An experimental study of rebate schemes would certainly be relevant in order to establish if there exist stable and significant "irrational" effects not caught by traditional theorizing. In addition, the prescriptive expected utility approach chosen here could be replaced by a descriptive prospect theoretic approach. See Daniel Kahneman and Amos Tversky (1979) Prospect Theory: An Analysis of Decision under Risk, Econometrica, 47. 263-292.

${ }^{18}$ Technically $t$ matters in the sense that the present value of the rebate varies with $t$. With $T \rightarrow \infty$, the present value of $x^{T} \alpha p \rightarrow 0$.

${ }^{19}$ The term uncertainty is used loosely as synonym for risk. See Frank H. Knight (1921) Risk, Uncertainty and Profit, Boston, MA: Hart, Schaffner \& Marx; Houghton Mifflin Company.

${ }^{20}$ Note that there exists an $\hat{x}<x^{T}$ that will leave the buyer indifferent between buying $\hat{x}$ or $x^{T}$ units. Note also that $\mu$ does not contain 1 or 0 . If $\mu=1$ or $\mu=0$, there is no uncertainty, either the threshold will be reached or it will not be reached with certainty.

${ }^{21}$ Under certainty, switching costs are given by $p\left(x^{*}\right)$. If $p\left(x^{*}\right)<\mu p\left(x^{*}\right)+(1-\mu) p$ holds, switching costs are lower under uncertainty ceteris paribus because the expected average price on the remaining units is higher (Note that switching costs decrease in price). Simplifying we get $(1-\mu) p\left(x^{*}\right)<(1-\mu) p$. Since $\alpha \neq 0$ by definition, it follows that $p\left(x^{*}\right)<p$ and therefore switching costs are lower under uncertainty. Dropping the ceteris paribus, a rational seller will clearly anticipate this and adjust the threshold and/or the rebate percentage accordingly.
} 
be lower than without uncertainty. ${ }^{22}$ Disregarding the possibility of asymmetric information, the uncertainty at $t=0$ is also known by the seller. As a result, irrespective of whether the ex ante probability of reaching $x^{T}$ is a function of $T$, the seller will consider this when setting up the rebate scheme. A demand shock can therefore only affect switching costs if it occurs at $t \neq 0$, that is, within the reference period. ${ }^{23}$ This is due to the fact that the seller can no longer adjust the rebate scheme accordingly. ${ }^{24}$ Even if expected demand is modelled as a stochastic process and therefore depends on remaining time, the reference period $T$ does as such not contribute to the calculation of switching costs.

\section{Conclusion}

As is clear from the previous section, retroactive rebates result in discontinuous and non-monotonic pricing schedules. As a result, marginal prices are nonincreasing in quantity up to and including the threshold $\left(p, p\left(x^{T}\right)\right)$, increasing for the next unit $\left(\frac{p\left(x^{T}\right)}{p\left(x^{T}+1\right)}<1\right)$ and non-decreasing afterwards $\left(p^{T}\right)$. Depending on the threshold and the rebate percentage, marginal price can be below marginal cost or even negative. This has negative effects on allocation ${ }^{25}$ and may cause a competition concern if switching costs result in market foreclosure. The pre-

\footnotetext{
${ }^{22}$ The same logic applies of course to endogenous demand. For instance, if total demand in $T$ is below $x^{T}, x^{T}$ could still be reached if the good can be stocked. Such a situation will, however, in most cases require the assumption of non-profit maximizing behavior on the seller side because there would be no reason not to adjust $T$ in such a way that demand equals $x^{T}$ (or to adjust $x^{T}$ to the demand in $T$ ). Even though this equilibrium argument is not further explored here, the assumption that $x^{T}$ is set to equal demand is incentive compatible and therefore very robust.

${ }^{23}$ The assumption made here is of course that only simply contracts can be written, that is, contracts that specify a real valued threshold, not a conditional one. If contracts can be written that are capable of adjusting the threshold contingent on events within the reference period, switching costs will be affected (since the threshold quantity will change) but not necessarily decreased.

${ }^{24}$ Under asymmetric information (expected) demand ex ante may already be unknown to the seller. The problem is then one of information asymmetry and not of uncertainty or time.

${ }^{25}$ Note that in the case of non-monotonic pricing schedules allocative efficiency is never fulfilled.
} 
vailing view, probably unduly extrapolated from the exclusive dealing literature, that the reference period should be part of an economic analysis of switching costs cannot be endorsed. Of course elapsed time will often be correlated with quantity, so that the suction effect may be the most pronounced towards the end of the period. However, such a correlation is only due to the fact that total quantity is non-decreasing in time.

Even if the reference period is not relevant for the assessment of switching costs, it is of course an essential part of any rebate system. If foreclosure is sought through a retroactive rebate system, the threshold $x^{T}$ to be met within a certain time period $T$ needs to be properly set, and that necessarily implies assessing expected demand within a particular time frame. Knowledge of the threshold level, the retroactive rebate rate and the amount already bought is a necessary but also sufficient condition for assessing switching costs in retroactive rebates. As a result, and to come back to the initial question addressed in this paper, the length of the reference period does not allow any conclusions with respect to switching costs.

As a result, the length of the reference period cannot be considered as a suitable indicator for sound competition policy because the quantities associated with a certain reference period will vary across industries. In addition, the length of the reference period is not a good approximation in any particular case either, because quantities may not be linearly and proportionally increasing in time. Last but not least, it is not clear why one should not directly revert to the causally relevant indicator, that allows comparisons across industries, namely quantity.

In fact, as this paper has argued, even rebate schemes with identical reference period may lead to completely different switching costs. Competition policy would, therefore, be ill-advised to consider the length of the reference period as an essential factor in assessing retroactive rebate schemes. 